\title{
Fruit Quality Detection and Gradation
}

\author{
Harshal S. Deshmukh ${ }^{*}$, Dr. S. W. Mohod ${ }^{2}$, Dr. N. N. Khalsa ${ }^{3}$

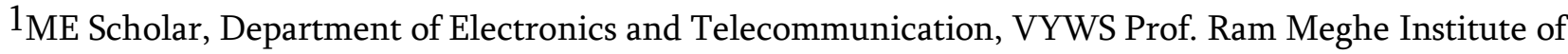 \\ technology \& Research, Badnera, Amravati, Maharashtra, India \\ 2,3Professor, Department of Electronics and Telecommunication, VYWS Prof. Ram Meghe Institute of \\ technology \& Research, Badnera, Amravati, Maharashtra, India
}

\section{Article Info}

Volume 7, Issue 4

Page Number: 383-388

Publication Issue :

July-August-2021

\section{Article History}

Accepted : 20 July 2021

Published : 27 July 2021

\section{ABSTRACT}

Grading and classification of fruits is based on observations and through experiences. The system exerts image- processing techniques for classification and grading the quality of fruits. Two-dimensional fruit images are classified on shape and color-based analysis methods. However, different fruit images have different or same color and shape values. Hence, using color or shape analysis methods are still not that much effective enough to identify and distinguish fruits images. Therefore, computer vision and image processing techniques have been found increasingly useful in the food industry, especially for applications in quality detection. Research in this area indicates the feasibility of using computer vision systems to improve product quality, the use of computer vision for the inspection of food has increased during recent years. This proposed work presents food quality detection system. The system design considers some feature that includes fruit colors and size, which increases accuracy for detection of roots pixels. Histogram of oriented gradients is used for background removal, for color classification, support vector machine is used.

Keywords : Gradation, Detection, Image Processing

\section{INTRODUCTION}

Agriculture and Horticulture is one of the largest economic sectors in the world, which plays the major role in economic development of India. Still in India, human experts use the traditional for inspection of fruits. This results wastage of time in the fields for checking the quality of the crops. In this Paper, an economic and safe way is used to analyse the fruit or vegetable quality that is based on color, shape and size. The most important physical property is fruit size while colour corresponds to visual property. Hence, classification of fruit is very important and necessary in evaluating agricultural produce for meeting quality standards and increasing the market value. This helps in planning, packaging, transportation and marketing operations. If the classification and grading is done through traditional techniques, the process will be very slow and may cause error prone. The labors classify fruits, vegetables based on color, size, etc. if these quality measures are mapped into automated system by using

Copyright: (C) the author(s), publisher and licensee Technoscience Academy. This is an open-access article distributed under the terms of the Creative Commons Attribution Non-Commercial License, which permits unrestricted non-commercial use, distribution, and reproduction in any medium, provided the original work is properly cited 
suitable programming language then the work will be faster, and error free. In recent years, computer machine vision and image processing techniques have been found increasingly useful in the fruit industry, especially for applications in quality inspection and shape sorting [1].

Color and shape characteristics of fruits are decisive for visual inspection. An efficient autonomous system for fruit sorting must be able to adequately identify both parameters. Shape of fruits can easily be obtained from a digital image using classical techniques for image processing. However, color identification involves many physical and psychological concepts, asking it difficult to properly model and process color in an image. There are wide varieties of color systems present for the grading of fruits based on colors. There are some techniques like Fuzzy logic, Neural Network; Based on Color Histogram, Genetic algorithm etc. Software development is highly important in this color classification system. The entire system is designed over MATLAB software to inspect the color and size of the fruit. Color of the fruit is very important in classification but since due to the similarity of colors between some fruits, the size also helps in solving this kind of problems. The color and size-based classification involves extracting the useful information from the fruit surface and classify it to the respective type. Nondestructive quality evaluation of fruits is important and very vital for the Food and agriculture industry. This project presents food quality detection system.

The system design considers some feature that includes fruit colors and size, which increases accuracy for detection of roots pixels. Histogram of oriented gradients is used for background removal, for color classification, support vector machine is used. The main idea behind the histogram of oriented gradient is that the local appearance and shape of object in an image can be described by the intensity distribution of gradients or direction of the contours. At present, most existing route quality detection and grading system have the disadvantage of low efficiency, low speed of grading, high Cost and complexity. Image processing of course solution for the automated size trading to provide accurate, reliable, consistent and quantitative information apart from handling large volumes, which may not be achieved by human grades. The hardware prototypes also created by using open CV ultra-low power micro controller [2].

\section{RELATED WORK}

John et. al. [3] In this work an automated grading system has been developed using image processing, which mainly focus on internal and external defects of a fruit. The system is having total no. of six CCD cameras. From that two of the cameras are mounted on the top, two on the right and another two cameras mounted on the left of the fruit. X-ray imaging is used for inspecting the biological defect. Image processing is used to analyze the fruits features: size, shape, color and the grade is determined based on the features. The developed system is built from a combination of advanced designs, expert fabrications and Automatic mechanical control. Frances et.al. [4] Accurate weighting of pieces in different sorts of conveyor belt or articulated Chains at fast speed is a key feature in many industrial processes. This paper presents a procedure to improve the performance, whether increasing speed or accuracy. The proposed solution includes a signal preprocessing based on a previous ARMA modelling and of the weighting Subsystem response plus a power line noise removal and a simple sample averaging in the plateau. The procedure has been tested of line using aerial signals acquired from a prototype machine. Wong et. al. [5] As a smart consumer, there is always a need for use to identify 
the quality of the goods we want to buy, such as trying to choose the best mango amongst the others. With the popularity of the mobile phone and the maturity in wireless messaging technology, it is no more a dream for us to get the information what we want anywhere, anytime. This paper proposes a new mobile data service that Includes signal processing service via MMS i.e. multimedia messaging service and SMS i.e. short messaging service. This paper contains the study, design, construction and analysis of a fully automated consumer-based wireless prototype system with interconnect the signal processing tools with consumer using MMS and SMS technology. The system with signal processing application processes the information sent by the consumer using MMS. Then it sends by the grading result to the consumer using SMS.

\section{Proposed Methodology}

Nondestructive quality evaluation of fruits is important and very vital for the Food and agriculture industry. This project presents food quality detection system. The system design considers some feature that includes fruit colors and size, which increases accuracy for detection of roots pixels. Histogram of oriented gradients is used for background removal, for color classification support vector machine is used. The main idea behind the histogram of oriented gradient is that the local appearance and shape of object in an image can be described by the intensity distribution of gradients or direction of the contours. At present, most existing route quality detection and grading system have the disadvantage of low efficiency, low speed of grading, high Cost and complexity. Image processing of course solution for the automated size trading to provide accurate, reliable, consistent and quantitative information apart from handling large volumes, which may not be achieved by human grades. The hardware prototypes also created by using open $\mathrm{CV}$ ultralow power micro controller.

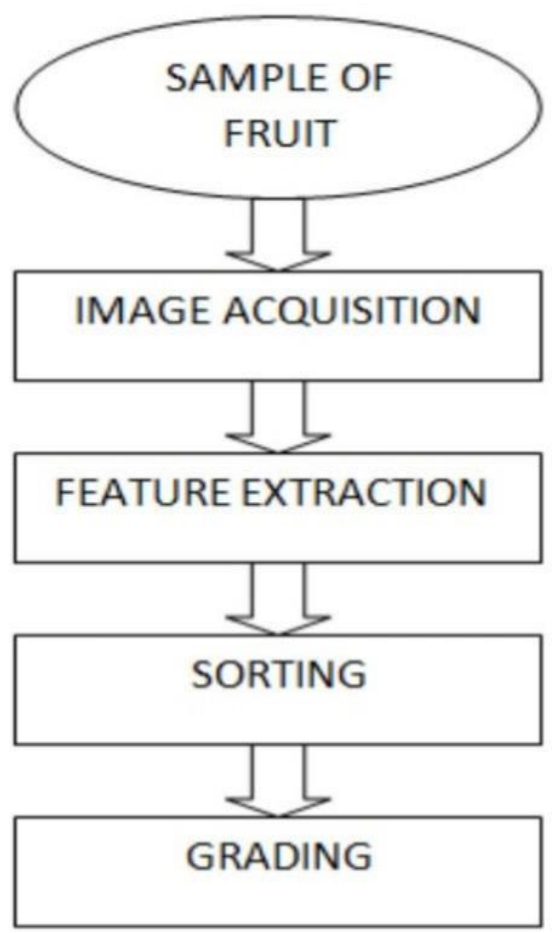

This proposed automated system is designed to overcome the problems of manual techniques. The system consists of several steps like feature extraction, sorting and grading. It is designed to combine three processes as shown below in a flow chart. Features like color of fruit, shape of fruit and size of fruit are extracted. Size features are extracted in height and width. Extracting the size of fruit is called grading. The flow chart of sorting and grading process is given in the above fig. 1.

\section{RESULT}

In this section, we give the overall performance of the system to detect fruit quality and grradation.. The graph below shows performances 
A. GRAPH FOR MSE

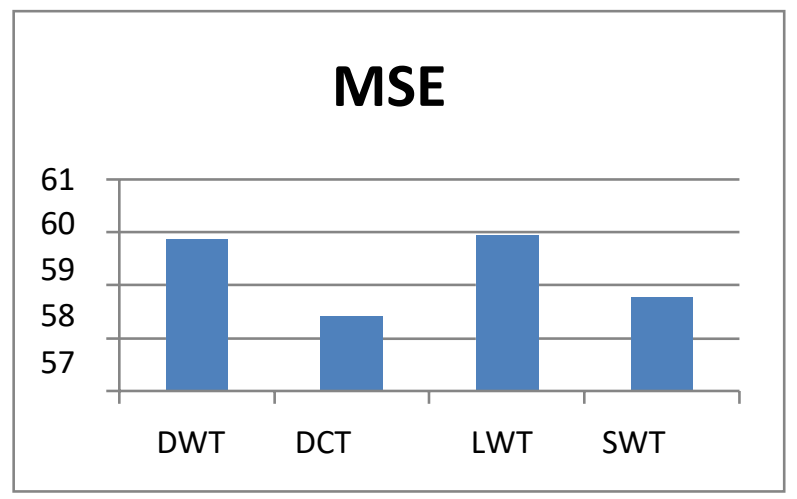

B. GRAPH FOR RMSE

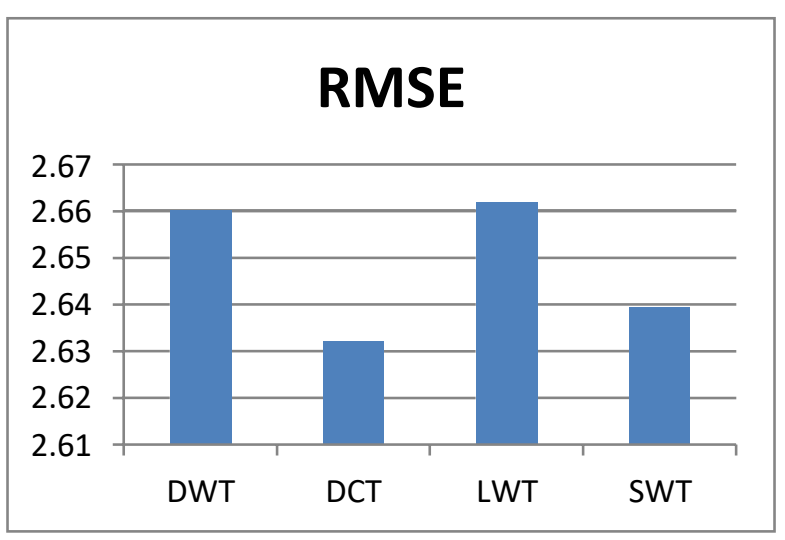

C. GRAPH FOR PSNR

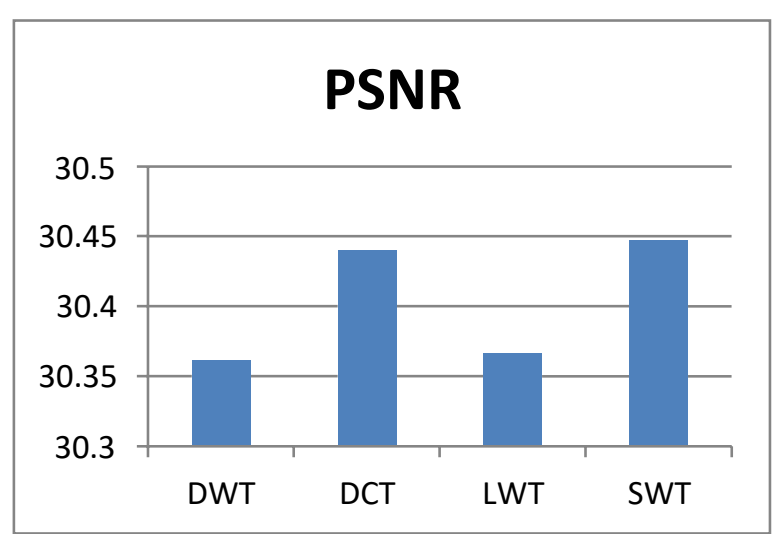

D. GRAPH FOR CORRELATION

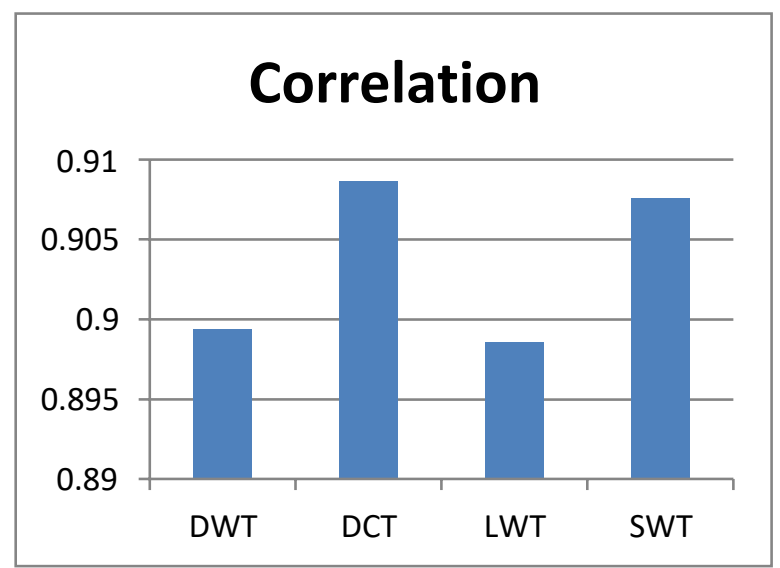

E. GRAPH FOR SNR

\section{SNR}

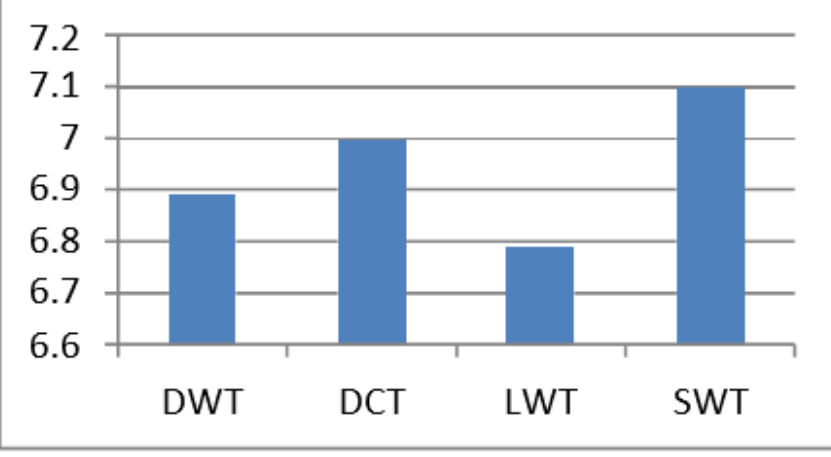

F. GRAPH FOR STANDARD DEVIATION (SD)

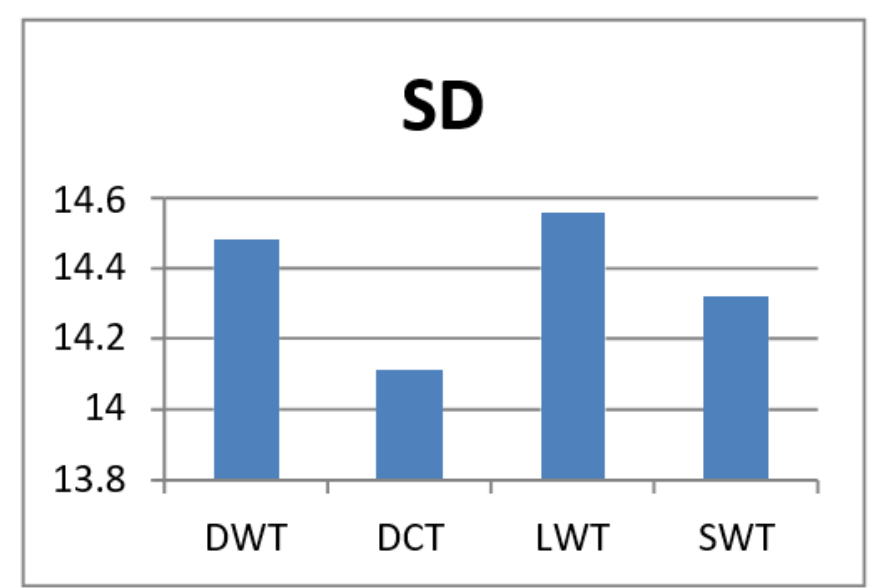




\section{CONCLUSION}

In this paper, different image processing-based classification techniques for fruit grading and sorting system is reviewed. Machine vision-based fruit grading systems are capable of replacing labor work for inspection of fruit grading. Different researchers used algorithms for image segmentation, feature extraction, training and classification of fruit disease. Out of morphological, color and texture feature, morphological gave highest accuracy rate. In color model, HIS (Hue, Saturation, Intensity) color model is commonly used for grading because it is related to human perception. In machine learning techniques, SVM (Support Vector Machine) gave highest accuracy, but Fuzzy gave lowest accuracy rate result, but it is easy to implement. Hence, using color or shape features analysis methods are still not effective enough to identify and distinguish fruits images. Therefore, computer vision and image processing techniques have been found increasingly useful in the food industry, especially for applications in quality detection.

\section{REFERENCES}

[1]. Naganur and sannakki, "Fruits Sorting and Grading using Fuzzy Logic”, International Journal of Advanced Research in Computer Engineering \& Technology (IJARCET) Volume 1, Issue 6, August 2012.

[2]. Sagare, Sunil N. Kore, "Fruits Sorting and Grading Based on Color and Size", International Journal of Emerging Technologies in Computational and Applied Sciences (IJETCAS), IJETCAS 12-333.

[3]. John B. Njoroge. Kazunori Ninomijya. Naoshi Kondo And Hideki Toita, "Automated Garding System using Image Processing," The society of Instrument and Control Engineers (SICE2002), Osaka, Japan, August 2002, pp 1346-1351.
[4]. J. V. Frances, J. Caple, E. Soria, M. Martinez, A. Rosado, A.J. Serrano, J. Calleja, M. Diaz, "Application of ARMA modelling to the improvement of weight estimations infruti sorting and grading machinery," IEEE2000.

[5]. Wong Bing Yit, NurBadariah Ahmad Mustafa, Zaippatimah Ali, "Design and Development of a Fully Automated Consumer-based Wireless Communication System for Fruit Grading", ISCIT 2009, pp 364-369.

[6]. Rosli B. Razak ${ }^{1}$, Mahmod B. Othman², Mohd Nazari bin Abu Bakar, Mango Grading by Using Fuzzy Image Analysis, International Conference on Agricultural, Environment and Biological Sciences (ICAEBS'2012) May p.p. 2627, 2012

[7]. Z. May1, M. H. Amaran2, Oil Palm Fruit Grading System using Artificial Intelligence ${ }^{e e}$, International Journal of Video \& Image Processing and Network Security IJVIPNSIJENS Vol: 11 No: 03, 2011

[8]. Suzanawati Abu Hasana, Teoh Yeong Kina, Suraiya Sauddin@Sa'duddina, Nur Badariah Ahmad Mustafa, Kumutha Arumugam, Syed Khaleel Ahmed, Zainul Abidin Md Sharrif "Classification of Fruits using Probabilistic Neural Networks - Improvement using Color Features"

[9]. Monika Jhuria, Ashwani Kumar,Rushikesh Borse,"image processing for Smart Farming :Detection of disease and Fruit Grading "proceeding of the 2013 IEEE second international conference on image processing (ICIIP-2013)

[10]. Nur Badariah Ahmad Mustafa, Kumutha Arumugam, Syed Khaleel Ahmed, Zainul Abidin Md Sharrif "Classification of Fruits using Probabilistic NeuralNetworks Improvement using Color Features"

[11]. Brendon J. Woodford et al, 2010, "Fruit Image Analysis using Wavelets." 
[12]. Siti Sofiah, "Color Recognition Algorithm using a Neural Network Model in Determining the Ripeness of a Banana" Proceedings of the International Conference on Man-Machine Systems (ICoMMS) 11 - 13 October 2009, Batu Fer ringhi, Penang, MALAYSIA]

[13]. Yizhong Wang et al, 2009, Study on fruit quality measurement and evaluation based on color Identification, Proc. of SPIE Vol. 7513 75130F-1

[14]. D. Unay, B. Gosselin, 2006, Automatic defect segmentation of Jonagold apples on multispectral images: A comparative study, Postharvest Biology and Technology 42 271279

[15]. devrim Unay, Bernard Gosselin “Artificial Neural Network-Based Segmentation And Apple Grading By Machine Vision"

[16]. Hetal N. Patel, Dr. R.K.Jain, Dr. M.V.Joshi, "Fruit Detection using Improved Multiple Features based

[17]. Algorithm", International journal of computer applications Volume 13-No.2, January 2011.

[18]. S.Arivazhagan, R.Newlin Shebiah,S.Selva Nidhyanandhan and L.Ganesan , "Fruit Recognition using Color and Texture Features",Journal of Emerging Trends in Computing and Information Sciences Volume 1, No.2,October 2010.

[19]. Bindu Tiger and Toran Verma, "Identification and Classification of Normal and Infected Apples using Neural Network", International Journal of Science and Research (IJSR) Volume 2 issue 6, June 2013.

[20]. Sandoval, Z ;Prieto,F ;Betancur,J, "Digital Image Processing for Classification of Coffee Cherries", Electronics,Robotics and Automotive Mechanics Conference (CERMA),2010 on Morel.

\section{Cite this article as :}

Harshal S. Deshmukh, Dr. S. W. Mohod, Dr. N. N. Khalsa, "Fruit Quality Detection and Gradation", International Journal of Scientific Research in Computer Science, Engineering and Information Technology (IJSRCSEIT), ISSN : 2456-3307, Volume 7 Issue 4, pp. 383-388, July-August 2021. Available at doi : https://doi.org/10.32628/CSEIT217493 Journal URL : https://ijsrcseit.com/CSEIT217493 